HNO 2021 69 (Suppl 2):S47-S52

https://doi.org/10.1007/s00106-021-01030-3

Accepted: 28 January 2021

Published online: 21 May 2021

(c) The Author(s) 2021

\author{
Matti Sievert ${ }^{1} \mathbb{D} \cdot$ Miguel Goncalves $^{1} \cdot$ Benedicta Binder $^{1} \cdot$ Sarina K. Mueller' \\ Robin Rupp ${ }^{1} \cdot$ Michael Koch ${ }^{1}$ Stephan Dürr' · Maximilian Traxdorf' · \\ Markus Hecht ${ }^{2} \cdot$ Heinrich Iro' ${ }^{1}$ Antoniu-Oreste Gostian ${ }^{1}$ \\ ' Department of Otorhinolaryngology, Head and Neck Surgery, Friedrich Alexander University of Erlangen- \\ Nuremberg, Erlangen, Germany \\ ${ }^{2}$ Department of Radiation Oncology, Friedrich Alexander University of Erlangen-Nuremberg, Erlangen, \\ Germany
}

\title{
Salvage laryngectomy after primary radio- and radiochemotherapy
}

\section{A retrospective study}

\section{Supplementary Information \\ The online version of this article (https:// doi.org/10.1007/s00106-021-01030-3) includes the patient cohort. Article and supplementary material are available at www.springermedizin.de. Please enter the title of the article in the search field, the supplementary material can be found under "Ergänzende Inhalte".

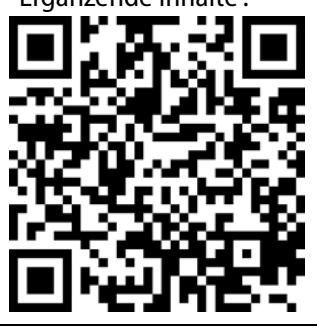

Salvage laryngectomy is a potential therapeutic option in treating recurrent and residual laryngeal cancer after radioand radiochemotherapy. Under ongoing competition with and rapid advancement of nonoperative treatment methods for head and neck malignancy in recent years, an assessment of oncologic outcomes and complications of salvage surgery is essential for clinical decisionmaking.

The German version of this article can be found under https://doi.org/10.1007/s00106021-01029-w.

\section{Background}

Despite an increasing tendency towards primary organ-preserving strategies for locally advanced squamous cell carcinoma of the larynx and hypopharynx, salvage surgery remains of great importance. Depending on the primary tumor's location and stage in the head and neck region, recurrence rates range from $25-50 \%$ after primary organ-preserving therapy [1]. In locoregional recurrence treatment, repetitive radiotherapy is often precluded, so effective oncologic outcomes can be achieved with salvage surgery [2]. After radiotherapy and chemotherapy, wound healing is impaired due to tissue fibrosis and decreased perfusion [3, 4]. This results in a significantly increased complication rate of up to $60 \%$ associated with markedly increased mortality and morbidity and significantly impaired quality of life [5]. The acceptance of the known disadvantages and risks of salvage surgery can only be justified by improved patient survival. Nowadays, immunotherapy is available as an alternative to surgery after failure of firstline therapy, in addition to palliative chemotherapy and re-irradiation [6]. Numerous clinical trials investigate the role of checkpoint inhibitors as a single treatment option and in combination with established treatment modalities. The current paradigm shift in the treat- ment of recurrent advanced laryngeal carcinoma puts the value of salvage surgery under critical review. This study aimed to determine the survival rate and evaluate preoperative prognostic factors for overall and disease-free survival of salvage surgery on residual or recurrent laryngeal cancer based on patients treated at the authors' institution. Secondary objectives included evaluation of surgical and general postoperative complications and duration of tube feeding.

\section{Study design and methods of investigation}

This is a retrospective cohort study of the University Hospital Erlangen (Department of Otolaryngology, Head and Neck Surgery), Germany. The study was approved by the local ethics committee (vote 246_20 Bc) and conducted in accordance with the Declaration of Helsinki.

\section{Study design}

The analysis was performed using a retrospective review of records from the tumor database at the authors' center of patients that underwent total or partial laryngectomy for laryngeal carcinoma between March 2001 and October 2019. Inclusion criteria were residual tumor or local recurrence after primary organ-preserving nonsurgical therapy. Residual tumor was defined 


\begin{tabular}{|c|c|c|}
\hline Gender & $n(\%)$ & \\
\hline Male & $27(81.8)$ & - \\
\hline Female & $6(18.2)$ & - \\
\hline Variable & Initial & Salvage \\
\hline Age & Mean \pm SD & Mean \pm SD \\
\hline Years & $61.2 \pm 10$ & $63.9 \pm 10$ \\
\hline T-Stage & $n(\%)$ & $n(\%)$ \\
\hline $\mathrm{T} 1$ & $1(3.0)$ & $5(15.1)$ \\
\hline $\mathrm{T} 2$ & $9(27.3)$ & $4(12.1)$ \\
\hline T3 & $12(36.4)$ & $9(27.3)$ \\
\hline T4a & $11(33.3)$ & $12(36.4)$ \\
\hline T4b & - & $3(9.1)$ \\
\hline$N$-Stage & $n(\%)$ & $n=17(\%)^{\mathrm{a}}$ \\
\hline NO & $16(48.5)$ & $15(88.2)$ \\
\hline N1 & $4(12.1)$ & - \\
\hline $\mathrm{N} 2 \mathrm{~b}$ & $7(21.2)$ & - \\
\hline $\mathrm{N} 2 \mathrm{c}$ & $6(18.2)$ & - \\
\hline N3b & - & $2(11.8)$ \\
\hline UICC & $n(\%)$ & $n(\%)$ \\
\hline I & $1(3.0)$ & $5(15.2)$ \\
\hline II & $4(12.2)$ & $4(12.1)$ \\
\hline III & $11(33.3)$ & $7(21.1)$ \\
\hline IVa & $17(51.5)$ & $12(36.4)$ \\
\hline $\mathrm{IVb}$ & - & $5(15.2)$ \\
\hline Grading & $n(\%)$ & $n=31(\%)$ \\
\hline G1 & - & $1(3.2)$ \\
\hline G2 & $15(45.5)$ & $10(32.3)$ \\
\hline G3 & $18(54.5)$ & $20(64.5)$ \\
\hline ECOG & $n=32(\%)$ & $n(\%)$ \\
\hline ECOG 0 & $9(28.1)$ & $4(12.1)$ \\
\hline ECOG 1 & $13(40.7)$ & $9(27.3)$ \\
\hline ECOG 2 & $8(25.0)$ & $15(45.5)$ \\
\hline ECOG 3 & $1(3.1)$ & $4(12.1)$ \\
\hline ECOG 4 & $1(3.1)$ & $1(3.0)$ \\
\hline \multicolumn{3}{|c|}{$\begin{array}{l}\text { UICC Union Internationale Contre le Cancer, ECOG Eastern Co-operative Oncology Group Performanc } \\
\text { Status, } T \text { tumor, } N \text { node, } G \text { grade, ND neck dissection } \\
\text { aNo ND in } 16 \text { cases }\end{array}$} \\
\hline
\end{tabular}

as a residual tumor portion that was macroscopically and histologically confirmed on panendoscopy immediately after primary radio- or radiochemotherapy. Recurrence was defined as tumor recurrence after a disease-free interval and inconspicuous panendoscopy following radio- and radiochemotherapy. Patients that were in the disease stage of distant metastasis or had unresectable tumors were excluded. After extirpation of the larynx and partial laryngectomy with or without concomitant pharyngectomy, the defects were primarily closed ternationale Contre le Cancer (UICC, [7]).

\section{Outcome parameters}

The study's primary endpoints were oncologic outcomes with rates of local and regional recurrence and distant metastases, as well as disease-free survival and overall survival. Survival was defined from the date of surgery to the date of death from any cause (overall survival), the occurrence of recurrence (diseasefree survival), or the date the patient was last known to be alive (overall survival and disease-free survival) or not dead from disease (disease-free survival). Patients that were alive at the time of evaluation were censored. Secondary endpoints represent the rate of postoperative complications, duration of tube feeding via PEG, and feeding at last follow-up.

\section{Statistical analysis}

The metric parameters are presented with the mean and standard deviation (SD). Frequencies of variables are presented in absolute and relative values ( $n$; \%). Survival curves were generated using Kaplan-Meier estimation and compared using the log-rank test. Associations between individual anatomic locations with overall survival and disease-free survival were tested on univariate Cox models. The association between nominal variables was tested using the chi-square test. A $p$-value less than 0.05 was considered statistically significant. For statistical analysis, IBM SPSS Statistics, version 25.0 (IBM Corporation, Armonk, NY, USA), was used.

\section{Results}

\section{Patient characteristics}

A total of 1327 squamous cell carcinomas of the larynx were diagnosed at the authors' center during the period in question: 1134 patients received primary surgical therapy, and 193 patients received primary organ-preserving therapy. Of these, 33 patients fulfilled the inclusion criteria (six females, 27 males; mean age, $63.9 \pm 10$ years, - Table 1). 
First-line therapy was intensity-modulated radiotherapy (up to $67.3 \pm 3.9 \mathrm{~Gy}$ total dose) in eight cases (24.2\%). Simultaneous radiochemotherapy (up to $69.4 \pm 3.4$ Gy total dose; cisplatin, 5-fluorouracil, docetaxel) was administered in 25 cases $(75.8 \%)$. Eight patients received prior induction chemotherapy.

In the case of tumor recurrence $(n=12 ; 36.4 \%)$, salvage surgery was performed after a mean of $7.2 \pm 3.8$ months. Patients with local recurrence $(n=20$; $60.6 \%$ ) underwent surgery at a mean of $25.4 \pm 18.1$ months after initial diagnosis. One patient (3\%) developed recurrence after a tumor-free interval of 27 years. - Table 1 shows patient and treatment characteristics at the time of initial diagnosis and salvage surgery. An overview of the patient cohort can be found in the Electronic Supplementary Material online.

\section{Salvage surgery}

A total of 33 salvage procedures were performed by complete $(n=31)$ or partial $(n=2)$ laryngectomy. Tumor-free margin (R0) could be achieved in a total of 30 cases $(90.9 \%)$. An R1 situation was found in three patients $(9.1 \%)$. In two cases, the R0 status initially diagnosed by intraoperative frozen section was R1 by the final histopathologic evaluation. In one patient, infiltration of the prevertebral fascia was detected intraoperatively. Neck dissection (level II-V) was performed in 17 cases (51.5\%) simultaneously with salvage surgery (14 bilateral, three unilateral, - Table 2). Positive neck status $(\mathrm{ycN}+)$ was diagnosed preoperatively on computed tomography in six patients (18.2\%) and was confirmed histopathologically in two cases $(6.1 \%)$. Patients were reclassified according to the histologic extent of tumor recurrence/ residue (rpT). Pathologic reclassification revealed: five (15.1\%) rpT1, four (12.1\%) rpT2, nine (27.3\%) rpT3, 15 (45.5\%) rpT4 (• Table 1). Pharyngeal reconstruction was performed by primary closure in 19 cases (57.6\%). Due to larger resection defects, free microvascular flap reconstruction was performed in 10 patients (30.3\%) and regional flap reconstruction was performed in five patients $(15.2 \%)$ us- ing pectoralis major myocutaneous flap $(n=2)$ or fasciocutaneous deltopectoral flap $(n=3)$ (- Table 2). Of these, one patient received free as well as pedicled flap reconstruction. A total of 28 patients $(84.8 \%)$ received PEG as part of therapy (- Table 3$)$. To achieve voice rehabilitation, six patients (18.2\%) underwent primary tracheoesophageal puncture, and one patient (3.0\%) underwent secondary tracheoesophageal puncture with the placement of a voice prosthesis (Provox 1, 2, and Vega; Atos Medical, Malmö, Sweden).

\section{Oncological outcome}

Of 33 patients, 16 (48.5\%) presented with tumor recurrence after salvage surgery. Local recurrence was observed in nine patients $(27.3 \%)$ after a mean of $83.4 \pm 87.8$ weeks, and regional cervical recurrence was observed in three patients $(9.1 \%)$ after $159.6 \pm 121.2$ weeks. Distant metastases were diagnosed in 11 patients $(33.3 \%)$ after a mean of $76.36 \pm 80.6$ weeks. The 1-, 2-, and 5-year overall survival rates were $68.7 \%, 47.9 \%$, and $24.2 \%$, respectively, with a median survival of 11 months (0-206 months). Disease-free survival at 1-, 2-, and 5 -years is $81.6 \%, 47.8 \%$, and $24.2 \%$, respectively (• Fig. 1). In univariate regression analysis, tumor manifestation in the hypopharynx $(p=0.033)$ was revealed to be a significant negative predictor of overall survival. Diseasefree survival was significantly reduced in the case of tumor manifestation in the hypopharynx $(p=0.041)$.

\section{Postoperative outcome}

An overview of all surgical and medical postoperative complications is presented in - Table 3. Complications occurred in a total of 25 patients (75.7\%). Pharyngocutaneous fistula was the most common complication at $72.7 \%(n=24)$. In 16 cases $(48.5 \%)$, the fistula occluded following purely conservative treatment after an average of $46.9 \pm 35.6$ days. Eight patients $(24.2 \%)$ required surgical fistula closure by pectoralis major or deltoid flap. No association was found between patients with and
HNO $2021 \cdot 69$ (Suppl 2):S47-S52

https://doi.org/10.1007/s00106-021-01030-3

(c) The Author(s) 2021

M. Sievert · M. Goncalves - B. Binder -

S. K. Mueller · R. Rupp - M. Koch · S. Dürr · M. Traxdorf $\cdot$ M. Hecht $\cdot$ H. Iro ·

A.-O. Gostian

Salvage laryngectomy after

primary radio- and radiochemotherapy. A retrospective study

\section{Abstract}

Background. Recurrent and residual laryngeal cancer after organ-preserving radio- or radiochemotherapy is associated with a poor prognosis. Salvage surgery is the most important therapeutic option in these cases.

Objective. The study assessed rates of recurrence and residual tumor as well as survival and complication rates after salvage laryngectomy at the authors' academic cancer center.

Materials and methods. A retrospective examination of all patients receiving laryngectomy between 2001 and 2019 due to tumor residuals or recurrence after primary radio- and radiochemotherapy was conducted.

Results. A total of 33 salvage procedures were performed. Defect reconstruction was performed by free flap surgery in $30.3 \%(n=10)$ and regional flap surgery in $15.2 \%(n=5)$. One patient received regional flap surgery and free flap surgery simultaneously. Overall survival after 1,2 , and 5 years was $68.7,47.9$, and $24.2 \%$, and disease-free survival was $81.6,47.8$, and $24.2 \%$, respectively, with $48.5 \%(n=16)$ postoperative tumor recurrences overall. Disease-free survival was significantly shorter for tumor extension into or onto the hypopharynx $(p=0.041)$. Postoperatively, $72.7 \%$ of patients developed a pharyngocutaneous fistula, of which $24.2 \%$ required surgical treatment. The hospital stay was $28.0 \pm 16.1$ days. Conclusion. Salvage laryngectomy is associated with a high rate of treatable complications and high morbidity. Nevertheless, considering the advanced tumor stages treated, it allows for respectable oncological results.

\section{Keywords}

Recurrence - Salvage therapy - Laryngeal neoplasms - Treatment outcome . Postoperative complications 


\section{Table 2 Characteristics of treatment}

\begin{tabular}{|c|c|c|}
\hline Primary therapy & $n$ & $\%$ \\
\hline Radiotherapy & 8 & 24.2 \\
\hline Radiochemotherapy ${ }^{\mathrm{a}}$ & 8 & 75.8 \\
\hline Induction ${ }^{\mathrm{b}}$ & 8 & 24.2 \\
\hline Irradiation dose (Gray) & Mean & $S D$ \\
\hline Tumor region & 68.9 & 3.6 \\
\hline Lymphatic drainage basin & 58.2 & 6.2 \\
\hline Time span (irradiation-surgery) & Mean & $S D$ \\
\hline Months & 18.6 & 16.9 \\
\hline Indication for salvage laryngectomy & $n$ & $\%$ \\
\hline Residuum & 12 & 36.4 \\
\hline Recurrence & 20 & 60.6 \\
\hline Second malignancy & 1 & 3.0 \\
\hline Resection status & $n$ & $\%$ \\
\hline Ro & 30 & 90.9 \\
\hline R1 & 3 & 9.1 \\
\hline Pharyngeal reconstruction & $n$ & $\%$ \\
\hline Primary suture & 19 & 57.6 \\
\hline Pedunculated flap ${ }^{c, d}$ & 5 & 15.2 \\
\hline Free flape & 10 & 30.3 \\
\hline Neck Dissection & $n$ & $\%$ \\
\hline Unilateral & 3 & 9.1 \\
\hline Bilateral & 14 & 42.4 \\
\hline \multicolumn{3}{|c|}{$\begin{array}{l}\text { R resection, SD standard deviation } \\
\text { aSimultaneous radiochemotherapy } \\
\text { bInduction chemotherapy (cisplatin, 5-fluorouracil, docetaxel) } \\
\text { 'Patient \#15 underwent pharyngeal reconstruction with one free and one pedicled flap } \\
\text { 'Three deltopectoral flaps and two pectoralis major flaps } \\
{ }^{\text {e}} \text { Four anterolateral femoral flaps and six radial flaps }\end{array}$} \\
\hline
\end{tabular}

without primary flap reconstruction in terms of fistula rate $(p=0.618)$. The patient with the secondary placement of a Provox prosthesis developed an extensive tracheoesophageal fistula. Patients were hospitalized for a mean of $28.0 \pm 16.1$ days, including $6.0 \pm 5.8$ days in the intensive care unit. After an average of $34.0 \pm 50.8$ months at last followup, 16 patients $(50.0 \%)$ were feeding entirely orally. The PEG was removed in these patients after an average of $39.7 \pm 20.8$ weeks. Five patients $(15.6 \%)$ were partially dependent on the PEG at the last presentation, and 11 patients (34.4\%) were completely PEG-dependent (• Table 3).

\section{Discussion}

The present study assesses the outcome of patients undergoing salvage surgery by total or partial laryngectomy after pri- mary nonsurgical treatment. The results show a 2- and 5-year overall survival of $47.9 \%$ and $24.2 \%$, respectively (• Fig. 1), and a disease-free survival of $47.8 \%$ and $24.2 \%$, respectively. Overall, $48.5 \%$ of patients had tumor recurrence postoperatively. A significantly lower 5-year survival rate was observed in the presence of hypopharyngeal involvement $(28.8 \%$ versus $10.9 \% ; p=0.041)$. Salvage surgery was associated with a high complication rate. Pharyngocutaneous fistula was the most common complication, requiring mostly conventional therapy only. In all, $50 \%$ of the treated patients were able to receive complete oral nutrition postoperatively.

In general, the rate of locoregional recurrence after organ-preserving therapy is $30-50 \%[1,8]$. If there is residual tumor or locoregional recurrence after primary radiochemotherapy, salvage surgery options should be explored. It remains a curative form of treatment after failure of primary nonsurgical therapy, provided that complete resection with negative margins appears achievable preoperatively. More than $70 \%$ of patients with residual disease or recurrence after radiochemotherapy have locally advanced tumors in the T3 and T4 categories [9]. The authors can confirm this with $27.3 \%$ of patients in an early (UICC I and II) and $72.7 \%$ of patients in a locally advanced tumor stage (UICC III and IV). In consideration of the study period and the development in radiation technology therein, the patients treated with salvage surgery in the context of the present study are comparable to the data of Putten et al. [5] for the study years 1990-2007. Thus, salvage surgery remains an ongoing surgical treatment option for the oncologic surgeon, albeit challenging and associated with complications. Overall oncologic outcomes across therapeutic regimens are unsatisfactory. In summary, the overall survival of $48-49 \%$ is reported for purely laryngeal carcinomas and $17-26 \%$ with hypopharyngeal involvement $[1,10]$. Alternatively, repeat radio- or radiochemotherapy may be offered in curative intent. A comprehensive meta-analysis on the outcomes of re-radiation was recently published by Grün et al. These colleagues reported 2- and 5 -year overall survival rates of $47-57 \%$ and $23 \%$, respectively, after intensitymodulated radiotherapy with concomitant chemotherapy [11]. Of note are the associated side effects, some of which are severe, with acute severe reactions in up to $73 \%$. Acute life-threatening complications are described in up to $11 \%[11,12]$. According to Kowalski et al., palliative therapy alone resulted in a median survival of only 3.8 months in 797 patients with recurrent head and neck malignancy and should be recommended with caution if operability is possible [13].

Difficult intraoperative preparation due to scarring post-radiogenic changes and reduced tissue perfusion is characteristic of salvage surgery [2]. This causes significantly increased postoperative complication rates with wound healing disorders, lymphedema, and especially the formation of pharyngo- 

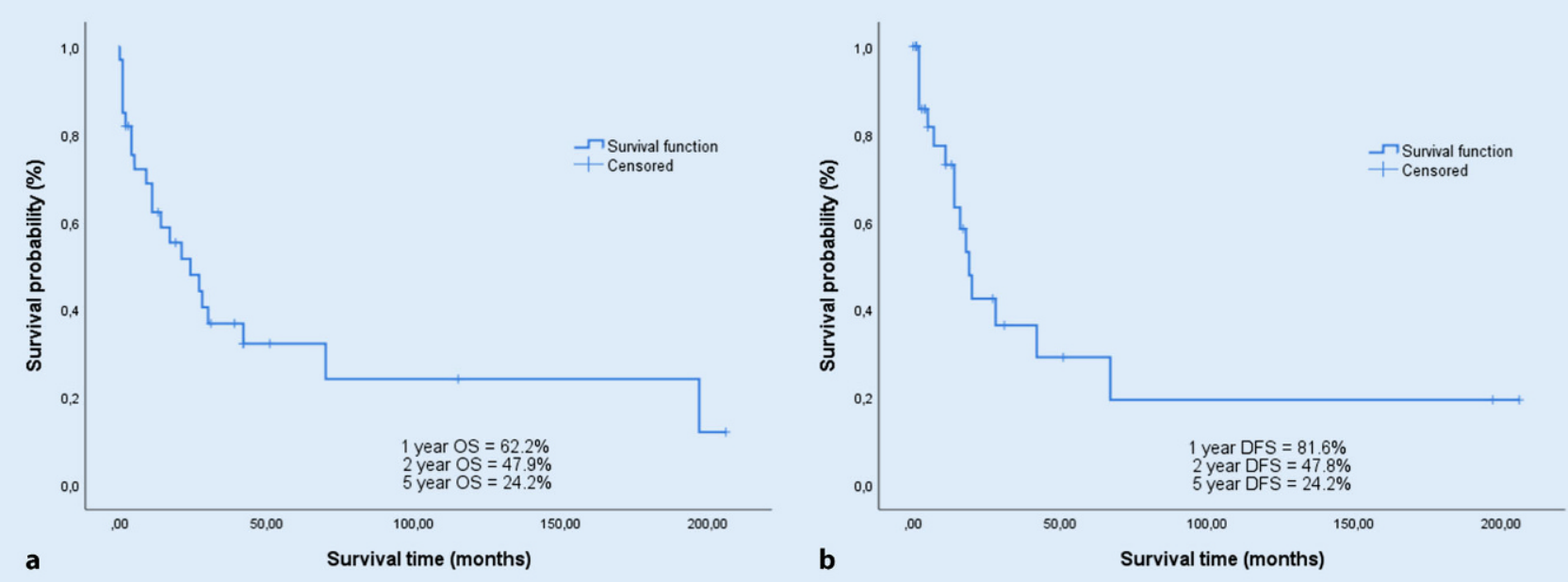

Fig. $1 \Delta$ Overall survival (a) and disease-free survival (b)

\begin{tabular}{|c|c|c|}
\hline Surgical complications & $n(\%)$ & Duration in days (Mean $\pm S D$ ) \\
\hline Fistula without surgical revision & $16(48.5)$ & $46.9 \pm 35.6$ \\
\hline Fistula with surgical revision & $8(24.2)$ & $201.0 \pm 170.9$ \\
\hline Esophagotracheal fistula & $1(3.0)$ & - \\
\hline Wound healing disorders & $14(42.4)$ & - \\
\hline Medical complications & $n(\%)$ & \multirow[t]{3}{*}{ - } \\
\hline Pulmonary artery embolism & $1(3.0)$ & \\
\hline Stroke & $2(6.1)$ & \\
\hline \multirow[t]{2}{*}{ Duration of inpatient stay } & \multirow[t]{2}{*}{ - } & Duration in days (Mean $\pm S D$ ) \\
\hline & & $28.0 \pm 16.1$ \\
\hline \multirow[t]{2}{*}{ Duration of stay in intensive care unit } & \multirow[t]{2}{*}{-} & Duration in days (Mean $\pm S D$ ) \\
\hline & & $6.0 \pm 5.8$ \\
\hline PEG Supply & $n(\%)$ & Duration in weeks (Mean $\pm S D$ ) \\
\hline Total & $28(84.8)$ & \multirow[t]{4}{*}{$39.7 \pm 20.8$} \\
\hline Before salvage surgery & 19 (57.6) & \\
\hline At salvage surgery & $8(24.2)$ & \\
\hline After salvage surgery & $1(3.0)$ & \\
\hline Nutrition at last presentation & $n=32(\%)$ & \multirow[t]{4}{*}{-} \\
\hline Completely via PEG tube & $11(34.4)$ & \\
\hline Partially via PEG tube & $5(15.6)$ & \\
\hline Normal or soft food (= PEG removed) & $16(50.0)$ & \\
\hline \multicolumn{3}{|l|}{ PEG percutaneous endoscopic gastrostomy } \\
\hline
\end{tabular}

cutaneous fistulas, which is the most common surgical complication [4].

Conservative therapy is the primary treatment in these cases, so surgical treatment is necessary for only about onethird of all fistulas $[4,14,15]$. In particular patients with a fistula requiring revision showed a prolonged healing course with a significant reduction in quality of life [15]. For example, the reconstruction of the pharynx with fresh tissue, for example, by pectoralis major flap, has a protective effect on the fistula rate [15]. In terms of the expected complications after salvage surgery and maintaining an acceptable quality of life and nutrition, PEG placement also contributes here [16, 17]. Two-thirds of patients were only partially, or not at all, dependent on tube feeding at their last presentation, after an average of 25 months.
Due to the problem of preoperative "understaging" caused by post-radiogenic edema and scaring changes, as well as the often multicentric tumor sites of recurrences, total laryngectomy remains the preferred procedure in salvage surgery of laryngeal carcinoma [10, 18, 19]. The results of this rare and challenging therapy must be interpreted in light of the retrospective study design and the inevitable limitations associated with it. This also results in a limited number of patients, which corresponds to comparable studies on this topic but impairs the analysis of individual factors influencing the oncological outcomes considered. Another aspect is the considerable period of retrospective data collection, which includes significant developments in radiation oncology. Nevertheless, the characteristics of patients to be treated are comparable to those in the 1990s and early 2000s. Salvage surgery for laryngeal cancer remains a treatment option that still retains its value today over alternative re-irradiation options and should be discussed in detail with the patient in these challenging situations.

\section{Practical conclusion}

\footnotetext{
- Salvage laryngectomy remains the current best therapeutic strategy in curative intent for residuals and recurrences after organ preservation protocols and should be considered as a therapeutic option.
} 
- In particular, patients with small, strictly laryngeal tumors without cervical metastasis benefit from salvage laryngectomy.

- Complications, especially pharyngocutaneous fistulas, are frequent but can be successfully treated conservatively.

\section{Corresponding address}

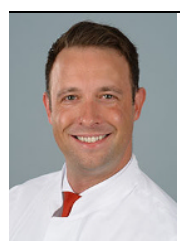

Dr. med. Matti Sievert

Department of Otorhino-

laryngology, Head and Neck

Surgery, Friedrich Alexander

University of Erlangen-

Nuremberg

Waldstraße 1, 91054 Erlangen, Germany

matti.sievert@uk-erlangen.de

Funding. Open Access funding enabled and organized by Projekt DEAL.

\section{Declarations}

Conflict of interest. M. Sievert, M. Goncalves, B. Binder, S.K. Mueller, R. Rupp, M. Koch, S. Dürr, M. Traxdorf, M. Hecht, H. Iro, and A.-O. Gostian declare that they have no competing interests.

This retrospective study was performed after consulting the relevant ethics committee and in accordance with national law, as well as the Declaration of Helsinki.

The supplement containing this article is not sponsored by industry.

Open Access. This article is licensed under a Creative Commons Attribution 4.0 International License, which permits use, sharing, adaptation, distribution and reproduction in any medium or format, as long as you give appropriate credit to the original author(s) and the source, provide a link to the Creative Commons licence, and indicate if changes were made. The images or other third party material in this article are included in the article's Creative Commons licence, unless indicated otherwise in a credit line to the material. If material is not included in the article's Creative Commons licence and your intended use is not permitted by statutory regulation or exceeds the permitted use, you will need to obtain permission directly from the copyright holder. To view a copy of this licence, visit http://creativecommons.org/licenses/by/4.0/.

\section{References}

1. Goodwin WJ Jr. (2000) Salvage surgery for patients with recurrent squamous cell carcinoma of the upper aerodigestive tract: when do the ends justify the means? Laryngoscope 110:1-18

2. Esteller E, Vega MC, López M et al (2011) Salvage surgery after locoregional failure in head and neck carcinoma patients treated with chemoradiotherapy. Eur Arch Otorhinolaryngol 268:295-301

3. Fung K, Teknos TN, Vandenberg CD et al (2007) Prevention of wound complications following salvage laryngectomy using free vascularized tissue. Head Neck 29:425-430

4. Paydarfar JA, Birkmeyer NJ (2006) Complications in head and neck surgery: a meta-analysis of postlaryngectomy pharyngocutaneous fistula. Arch Otolaryngol Head Neck Surg 132:67-72

5. Putten L, Bree R, Doornaert PA et al (2005) Salvage surgery in post-chemoradiation laryngeal and hypopharyngeal carcinoma: outcome and review. Acta Otorhinolaryngol Ital 35:162-172

6. Forster MD, Devlin MJ (2018) Immune checkpoint inhibition in head and neck cancer. Front Oncol 8:310

7. Doescher J, Veit JA, Hoffmann TK (2017) Die 8. Ausgabe der TNM-Klassifikation: Neuerungen für das Fachgebiet Hals-Nasen-Ohren-Heilkunde, Kopf-und Halschirurgie. HNO65:956-961

8. Hoffman HT, Porter K, Karnell LH et al (2006) Laryngeal cancer in the United States: changes in demographics, patterns of care, and survival. Laryngoscope 116:1-13

9. Putten L, Bree R, Kuik DJ et al (2011) Salvage laryngectomy: oncological and functional outcome. Oral Oncol 47:296-301

10. Santoro R, Bini B, Mannelli G et al (2014) Salvage surgery after unsuccessful radiotherapy in early glottic cancer. B-ENT 10:113-120

11. Grün A, Kuhnt T, Schlomm T et al (2020) Repeat radiation for local recurrence of head and neck tumors and in prostate cancer. Dtsch Arztebl Int 117:167-174

12. Ohizumi $Y$, Tamai $Y$, Imamiya $S$ et al (2002) Complications following re-irradiation for head and neck cancer. Am J Otolaryngol 23:215-221

13. Kowalski LP, Carvalho AL (2000) Natural history of untreated head and neck cancer. Eur J Cancer 36:1032-1037

14. Dirven R, Swinson BD, Gao K et al (2009) The assessment of pharyngocutaneous fistula rate in patients treated primarily with definitive radiotherapy followed by salvage surgery of the larynx and hypopharynx. Laryngoscope 119:1691-1695

15. Patel UA, Moore BA, Wax M et al (2013) Impact of pharyngeal closure technique on fistula after salvage laryngectomy. JAMA Otolaryngol Head NeckSurg 139:1156-1162

16. Hausmann J, Kubesch A, Goettlich CM et al (2020) Quality of life of patients with head and neck cancer after prophylactic percutaneous-gastrostomy. Eur JClin Nutr 74:565-572

17. Mekhail TM, Adelstein DJ, Rybicki LA et al (2001) Enteral nutrition during the treatment of head and neck carcinoma: Is a percutaneous endoscopic gastrostomy tube preferable to a nasogastric tube? Cancer 91:1785-1790

18. Holsinger FC, Funk E, Roberts DB et al (2006) Conservation laryngeal surgery versus total laryngectomy for radiation failure in laryngeal cancer. Head Neck 28:779-784

19. Zbären P, Nuyens M, Curschmann J et al (2007) Histologic characteristics and tumor spread of recurrent glottic carcinoma: analysis on wholeorgan sections and comparison with tumor spread of primary glottic carcinomas. Head Neck29:26-32 